\title{
THE HYDRAULICS OF NATURE-LIKE FISHWAYS
}

\author{
Xi Mao', Sheng Huang ${ }^{1}$, Yuchen Xü, Zhong Cheng ${ }^{1}$, Jiehao Zhang ${ }^{2}$, Xiaofan Liư ${ }^{3}$, \\ Yong Wang ${ }^{4}$, Kai Tang ${ }^{1}$, Yunbo Yang ${ }^{1}$, Lu Jiang ${ }^{1}$ and Zetang Guan ${ }^{1}$
}

1. Sichuan Agricultural University, College of Water Conservancy and Hydropower Engineering, Yaan, Road Xinkang 46, China; maowhiteknight@163.com

2. Yunnan Institute of Water \& Hydropower Engineering Investigation, Design and Research, Kunming, Road Qinnian 376, China

3. Yalong River Hydropower Development Company, Ltd., Chengdu, Road Shuanglin 288, China

4. Sichuan Agricultural University, College of Forestry, Chengdu, Road Huimin 211, China

\section{ABSTRACT}

Nature-like fishway arrangements are commonly used because these structures imitate the characteristics of natural rivers and effectively allow fish to migrate past river sections blocked by hydraulic structures. In this paper, physical models were analyzed, and the velocity distributions of two different fishway structures (Types I and II) were compared. Results showed that the maximum mainstream velocity of the Type I structure was 5.3\% lower than that of the Type II structure. However, the average mainstream velocity of the Type I structure was $21.1 \%$ greater than that of the Type II structure. The total per-cycle length of the mainstream path in the Type II structure was 2.1 times greater than that of the Type I structure, which indicated that the length of the mainstream path was somewhat proportional to the average velocity of the mainstream. When the flow rate was kept constant, the average velocity of the mainstream decreased by increasing the total length of the mainstream caused by the internal structure of the fishway, and the average velocity of the mainstream increased when the total length of the mainstream was shortened.

\section{KEYWORDS}

Ecological restoration, Energy dissipation, Flow velocity, Hydraulics, Nature-like fishway

\section{INTRODUCTION}

The construction of hydraulic structures, such as gates and dams, alters the natural state of rivers, blocking the migration channels of aquatic organisms, especially fish. Fishways are effective engineering measures that restore fish migration channels [1]. Commonly used fishways can generally be considered either technical fishways or nature-like fishways [2] [3].

Nature-like fishways use the roughness of river bottom and bank, as well as river stones, to dissipate energy [4]. Although nature-like fishways are prone to get dry when the upstream water level is low, construction is inexpensive and the necessary materials can be obtained nearby [5]. These fishways are suitable for the migration of many fish species, and fish may pass through such fishways continuously with high efficiency [6]. Water flows in nature-like fishways are highly diverse. Fishway water flow conditions are suitable for most fish species, and rock arrangement patterns can be rearranged to best suit specific species [7]. The main factors influencing fishway flow conditions are the total difference in water level between the beginning and the end of the 


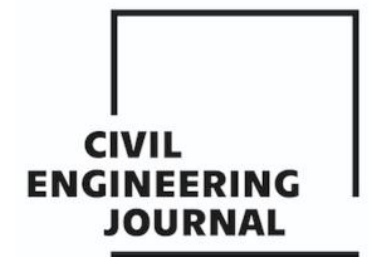

Article no. 63

THE CIVIL ENGINEERING JOURNAL 4-2021

fishway, the average water level difference within a single pond, the arrangement of the internal structure of the fishway, and the average slope of the fishway. In this paper, the internal structures of nature-like fishways were analyzed to characterize the different flow conditions produced by different structures.

\section{MODEL TEST}

In this study, the main fish-passing objects were schizothorax oconnoris and schizothorax macropogons, both of which belonged to migratory fish. The optimal swimming speed was $0.8 \mathrm{~m} / \mathrm{s}$, and the flow rate should be controlled in $0.5-0.8 \mathrm{~m}^{3} / \mathrm{s}[1]$. For the pool fishway, the water depth of the pool room should be determined by the height and habit of the fish object, generally $1.0-1.5 \mathrm{~m}$. For the natural-like fishways, the water depth in the fishways should be determined according to the ecological habits of the target fish species. The minimum water depth of the fishways can be appropriately increased when there are more bottom fish in the key fish-passing objects. The slope of natural-like fishways should be as gentle as possible, generally controlled within $2 \%[8]$.

Considering the fish species and habits, the average water depth $\mathrm{H}$ of this study was controlled at $0.109 \mathrm{~d}$, the flow rate was $0.03 \mathrm{~d}^{2}$, and the longitudinal bottom slope ratio was $2 \%$. The average height of baffle $h$ was $0.108 \mathrm{~d}$, so the ratio of submergence of baffles $\mathrm{h} / \mathrm{H}$ was 0.99 . For the targeted species of fish, the minimum design dimension of slot width of fishway was $0.28 \mathrm{~m}$, and the depth of flow downstream of the tip of the groyne or the central slot was $0.2 \mathrm{~m}$. The flow rate was measured by the triangular sharp-crested weir. The velocity was measured by a micro propeller flow meter, and the vertical average velocity of a measuring point was calculated by the "three-point method"[9].

The following two structures were used to simulate the nature-like fishway based on obstacle arrangement, as shown in Figure 1. The fishway structure with regular geometry could effectively divide the mainstream area and rest area in each level of the fish pool, which is conducive to more efficient migration of fish.

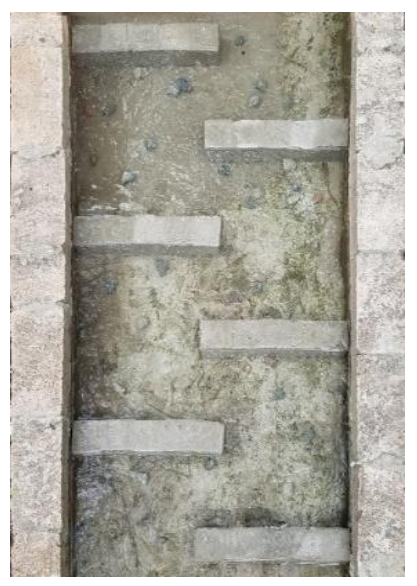

(a)Type I

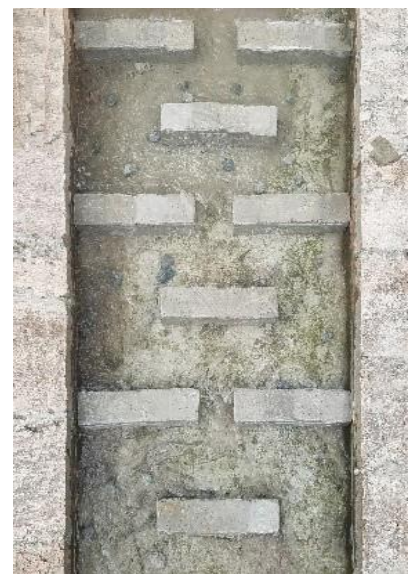

(b)Type II

Fig. 1 - Schematic image showing the two nature-like fishway structures.

The vertex on the right bank of the model was considered the origin of the coordinate plane; the $x$-axis was parallel to the direction of river flow, and the $y$-axis was perpendicular to river flow. Velocity was measured in a $0.077 d$ by $0.077 d$ grid, where $d$ was the width of the model. The specific size constants used are given in the section diagrams, as shown in Figure 2 and Figure 3. 


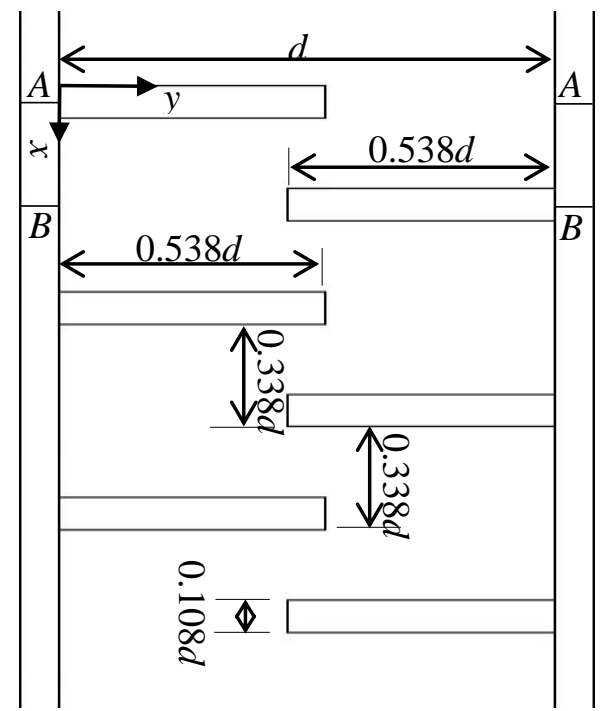

(a)- Type I

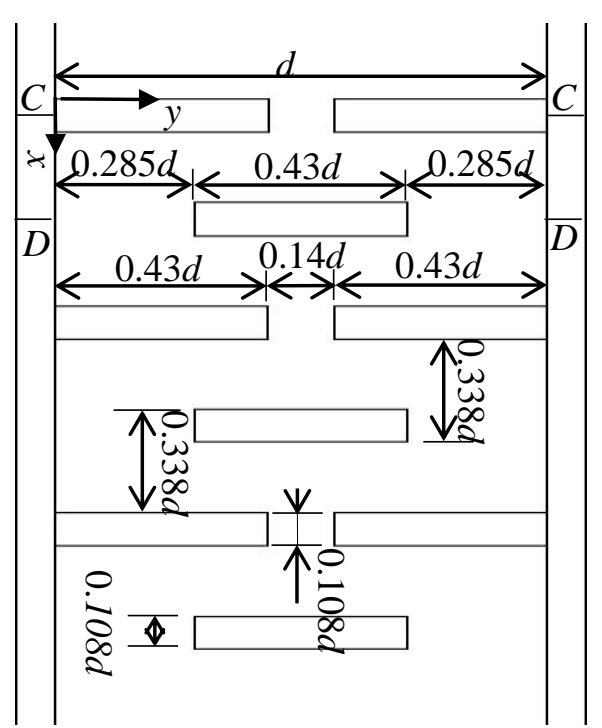

(b)- Type II

Fig. 2 - Schematic diagram showing the model structure.

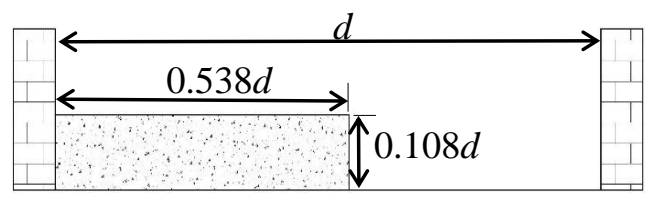

(a) - Section A-A

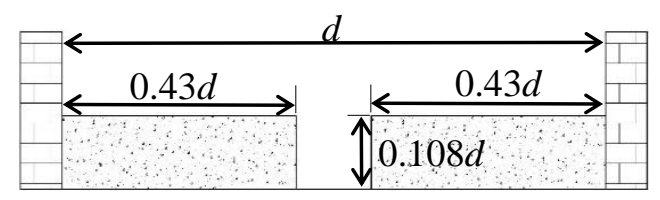

(c) - Section $C-C$

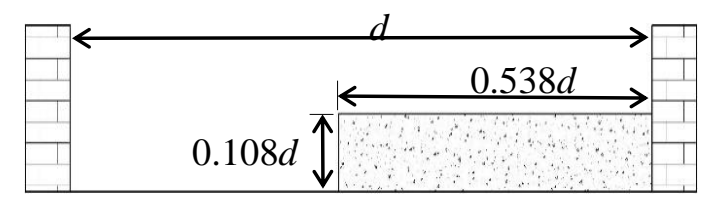

(b) - Section $B-B$

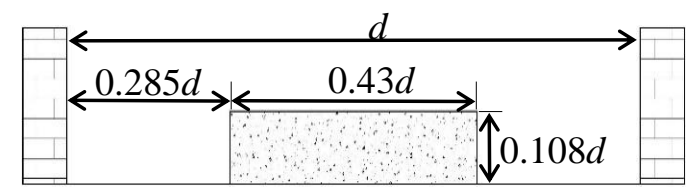

(d) - Section $D-D$

Fig.3 - The Section diagram of model structure.

\section{MODEL TEST RESULTS AND ANALYSIS}

\section{Flow velocity in each model cross-section}

When the structure of each pool in a fishway is the same, the flow velocity in the fishway changes regularly. Therefore, only one complete cycle was analyzed in this study. The variation of depth-averaged velocities in various cross-sections in the two models are shown in Figure 4. 


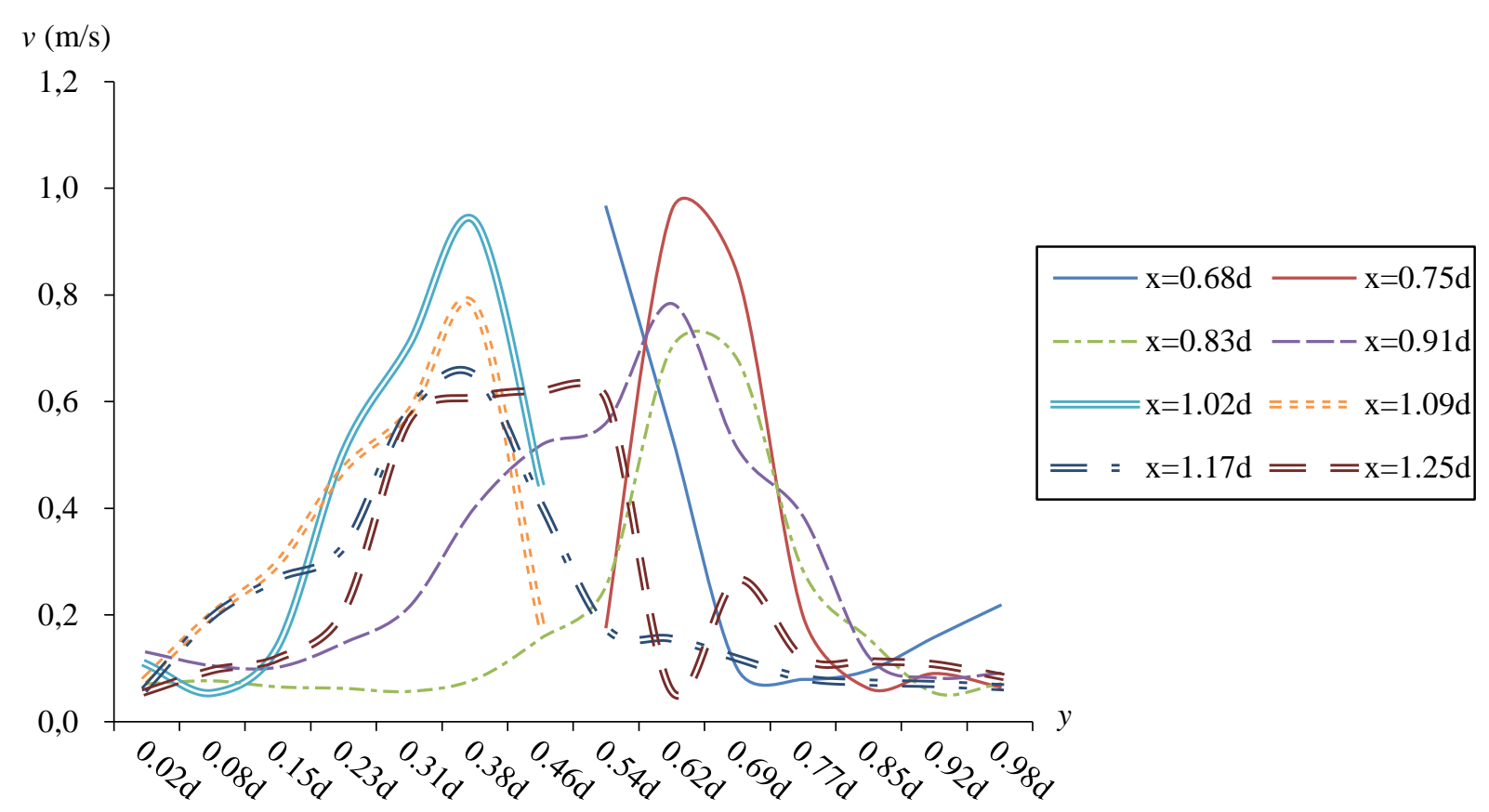

Fig. 4 (a) - Depth-averaged velocities variation chart of a period section (type I)

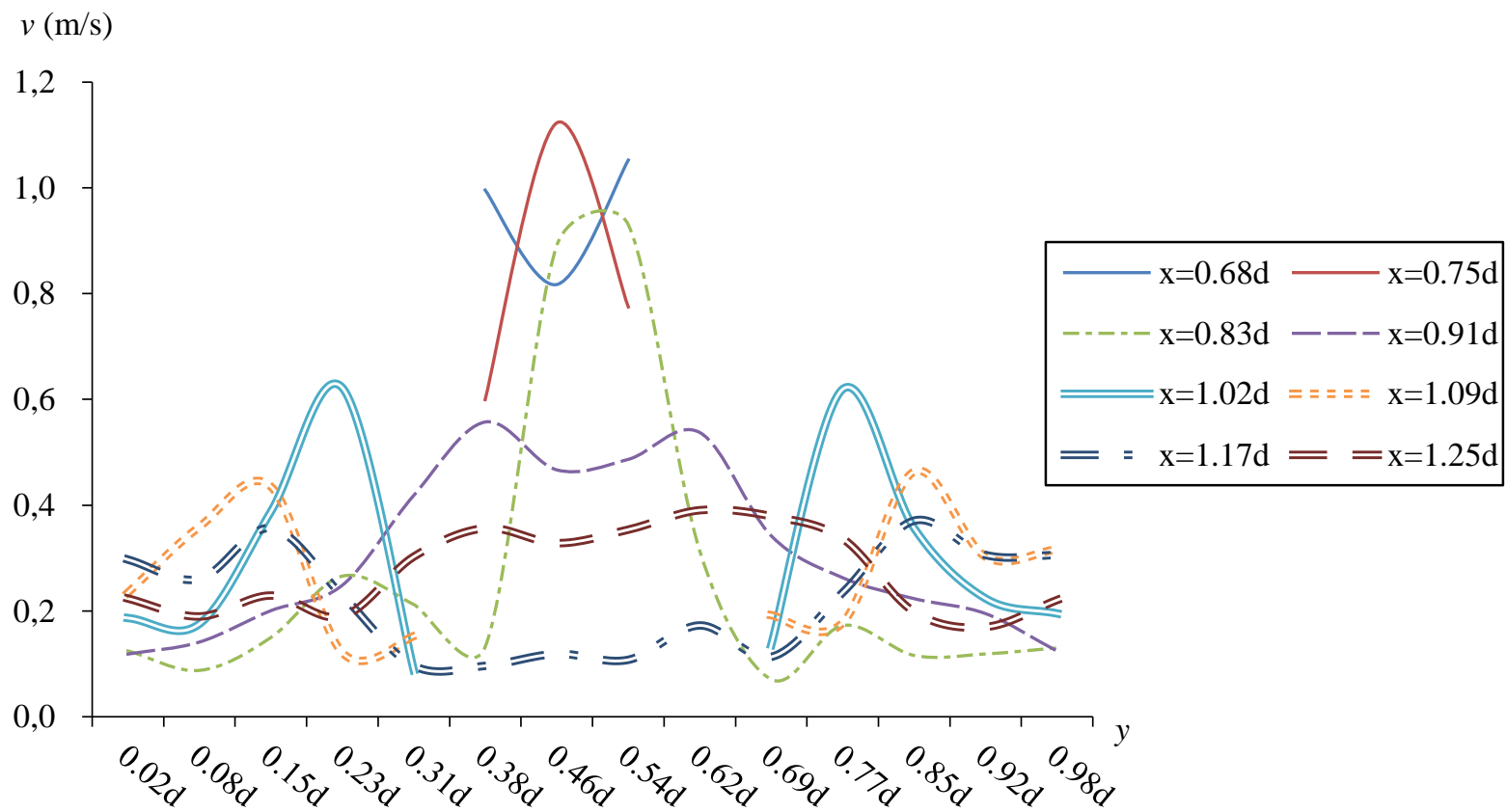

Fig. 4 (b) - Depth-averaged velocities variation chart of a period section (type II)

(1) In the Type I structure, the sectional velocity presented the trend of symmetry between the first and second halves of the section.

(2) In the Type I structure, the average water velocity during each cycle was roughly the same, decreasing little over the course of the cycle along the river.

(3) The cross-sectional water velocity diagram of the Type II structure was symmetrically distributed around the center of the river channel, with the maximum velocity located near the transition between sections. In the first half of each cycle, flow velocities were highest near the 
riverbank, decreasing towards the middle of the cycle. During the second half of each cycle, the flow velocities near the banks of the river were greater than that in the center of the river.

(4) Average flow velocities between sections in the Type II structure were roughly equivalent, with little decrease along the river channel; the average flow velocity in the first half of the cycle was greater than that in the second half.

\section{Mainstream flow velocity and overall velocity}

Variations in the velocity of the main flow are shown in Figure 5, and the distributions of velocity measurement in the two different nature-like fishway structures are shown in Figure 6.

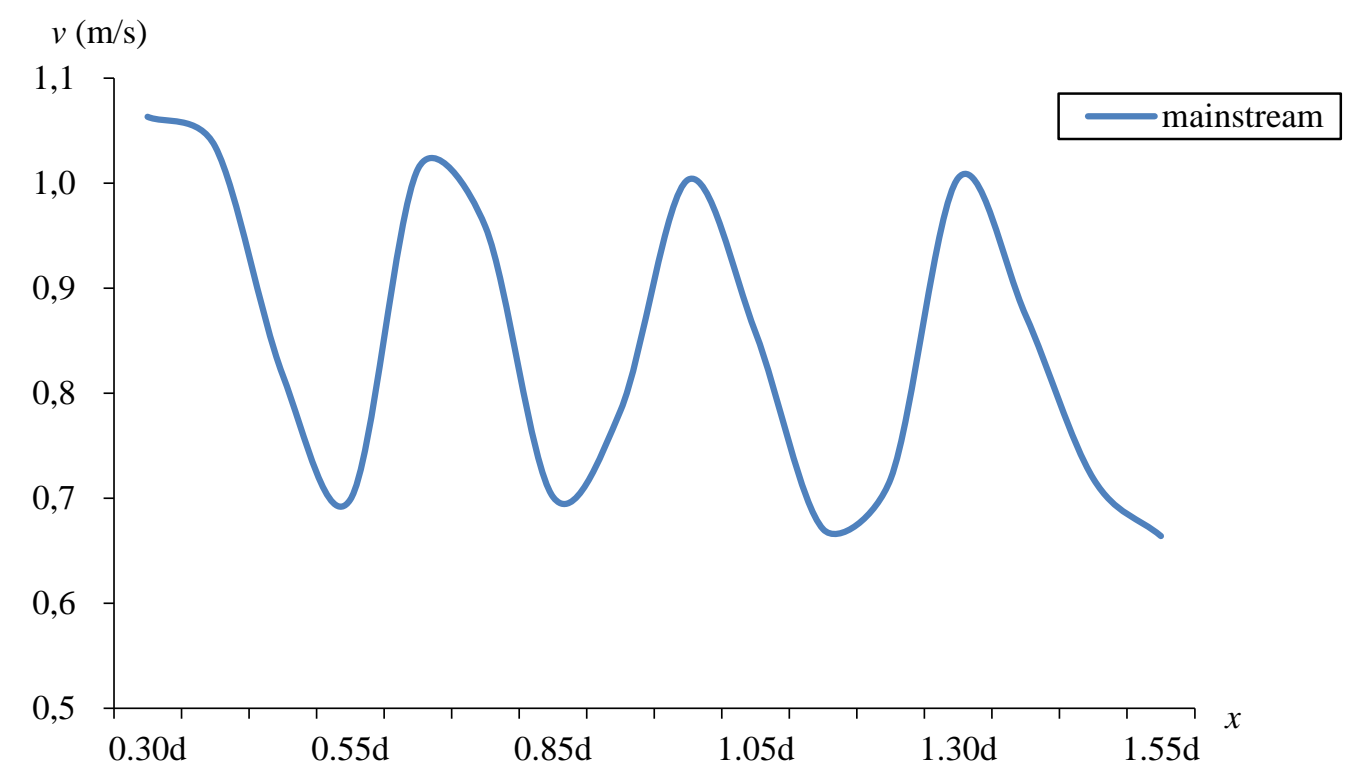

Fig. 5- (a) - Changes in mainstream flow velocity over the course of the cycle (type I)

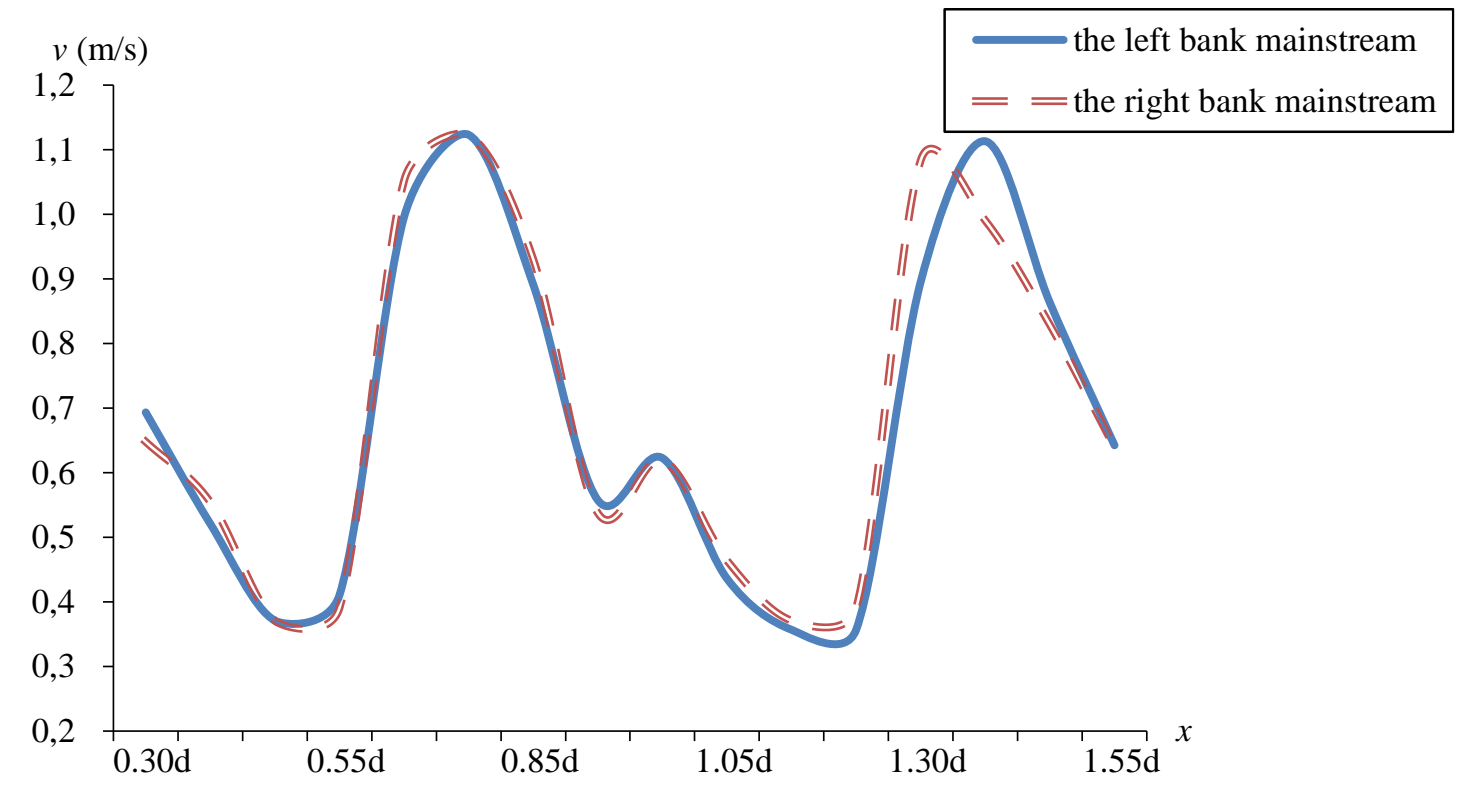

Fig. 5 - (b) - Changes in mainstream flow velocity over the course of the cycle (type II) 
Article no. 63

CIVIL

ENGINEERING

THE CIVIL ENGINEERING JOURNAL 4-2021 JOURNAL

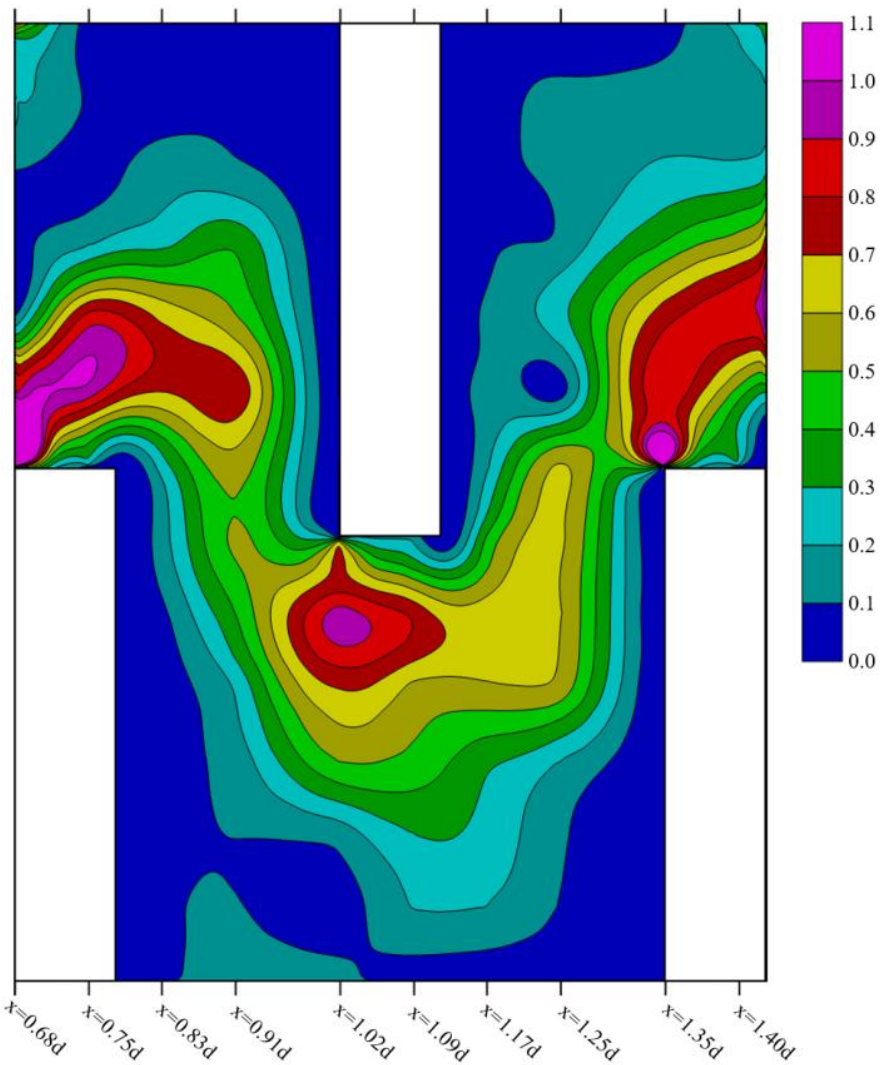

Fig.6 - Velocity plane map of (a) - type I ( $\mathrm{m} / \mathrm{s})$

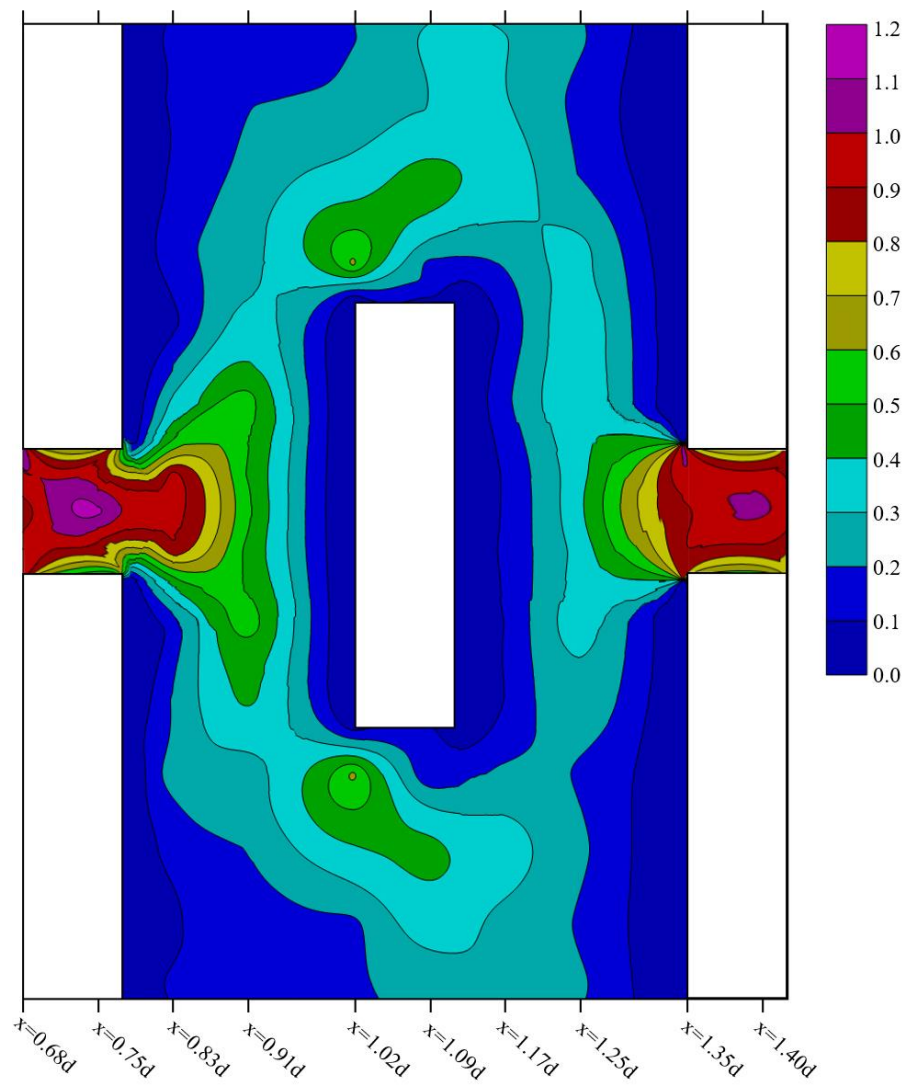

Fig.6 - Velocity plane map of (b) - type II ( $\mathrm{m} / \mathrm{s})$ 
Previous studies have shown that the flow velocities of most nature-like fishways in China are within the recommended range $(0.6-1.2 \mathrm{~m} / \mathrm{s})$ [10]. In the Type I structure, $9.65 \%$ of the total area had a flow velocity of $0.6-1.2 \mathrm{~m} / \mathrm{s}$, and the velocity distribution was relatively uniform. In the Type II structure, only $4.05 \%$ of the total area had a velocity of $0.6-1.2 \mathrm{~m} / \mathrm{s}$, and most of the changes in velocity in these areas were concentrated near obstacles where the cross-sectional pattern changed. Compared with Type I structures, more fish migration areas had high flow velocities in Type II structures. The remaining areas in Type II structures, with low flow rates, could be used as resting areas for migrating fish.

Water flow continuity was calculated using the following equation:

$$
Q=A \times v
$$

where $Q$ was the model flow rate, which was a fixed value; $A$ was the section area; and $v$ was the mean velocity in the section, and its value is the average velocity of the vertical average of different measuring points in the same cross-section.

The main flow of the water in the fish channel was analyzed first. When the main flow passed around an obstacle, the cross-sectional volume of the water flow was suddenly reduced due to the narrowing effect of the obstacle on the water flow channel. Because the flow rate did not change, the velocity of the water flow at the obstacle increased. Once the water flowed past the obstacle, the narrowing effect ceased, increasing the cross-sectional volume of the flow and decreasing flow velocity. Thus, flow velocity changed in a periodic manner corresponding to obstacle locations.

Because the bottoms and sides of the fishway were not completely smooth, layer resistance must be considered. Water loses energy as it flows downstream. Water flow head loss over the course of the cycle was thus calculated using the following equations:

$$
\begin{aligned}
& \square_{f}=\frac{v^{2} l}{C^{2} R} \\
& C=\frac{1}{n} R^{\frac{1}{6}} \\
& \square_{f}=\frac{n^{2} v^{2} l}{R^{\frac{4}{3}}}
\end{aligned}
$$

where $h_{f}$ was the frictional head loss; $C$ was the Xie Cai coefficient; $n$ was the roughness coefficient; / was the length of the flow path; and $R$ was the hydraulic radius.

When the water flow suddenly encounters a solid boundary, the distribution of flow velocities throughout the flow section changes rapidly. This concentrated resistance in a small area is known as local resistance [11]. The effects of local resistance on head loss in the fishway water flow were calculated using the following equation:

$$
h_{j}=\zeta \frac{v^{2}}{2 g}
$$

where $h_{j}$ was the local head loss; $\zeta$ was the loss coefficient along the flow path; and $g$ was the acceleration due to gravity (a constant).

The main flows of Type I and Type II nature-like fishway structures exhibited periodic fluctuations in velocity along the direction of water flow as shown in Figure 5 . This meant that both fishways reached the pseudo-uniform condition of flow. And the balance between the sum of local head loss $h_{j}$ and frictional head loss $h_{f}$ and the bottom drop at each fishway cycle was effective, namely the law of conservation of energy.

Due to its planar symmetry, the Type II structure had two mainstreams, on either side of the middle baffle, with similar velocity profiles.

The maximum mainstream flow velocity in the Type I structure was $1.063 \mathrm{~m} / \mathrm{s}$, and the average mainstream flow velocity was $0.815 \mathrm{~m} / \mathrm{s}$. The maximum mainstream flow velocity in the Type II structure was $1.123 \mathrm{~m} / \mathrm{s}$, and the average mainstream flow velocity was $0.673 \mathrm{~m} / \mathrm{s}$. Although the maximum flow velocity of the Type I structure was 5.3\% lower than that of the Type II structure, the average flow velocity of the Type I structure was $21.1 \%$ greater than that of the Type II structure. 


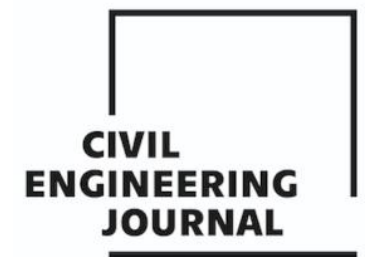

Article no. 63

THE CIVIL ENGINEERING JOURNAL 4-2021

This was due to the difference in the lengths of the mainstream path between the two structures. The main flow paths of both structures are shown in Figure 7. The Type I structure had one main flow path per cycle (1.02d), while the Type II structure had two main flow paths per cycle: the main flow path close to the left bank was $1.18 \mathrm{~d}$ long, while the main flow path close to the right bank was $1.21 d$ long (Figure $7 \mathrm{~b}$ ). Excluding the overlapping portion, the total length of the main flow path in the Type II structure was $2.17 \mathrm{~d}$. In total, the main flow path of the Type II structure was 2.1 times longer than that of the main flow path of the Type I structure. Thus, the maximum flow velocity in the Type I structure was lower than that in the Type II structure, but the average mainstream flow velocity was higher.

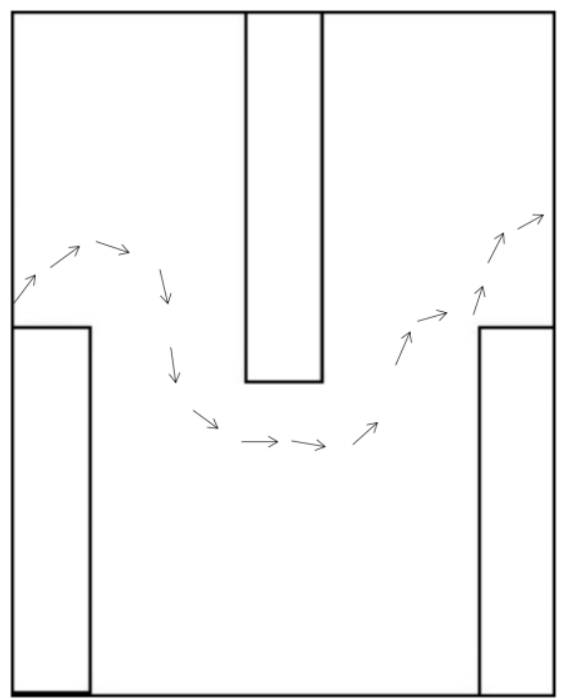

(a) type I

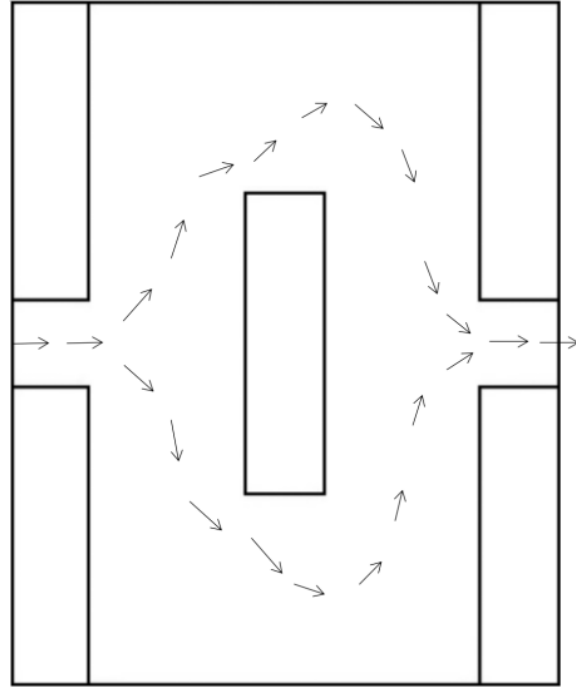

(b) type II

Fig.7 - Schematic showing mainstream flows in both structures.

\section{The volumetric energy dissipation rate}

The volumetric energy dissipation rate is generally used to judge the adaptability of pool fishway to fish passing objects, and its calculation formula is as follows:

$$
E=\frac{\rho g Q \Delta h}{V}
$$

where $E$ was the volumetric energy dissipation rate; $\rho$ was the density of water; $g$ was the gravitational acceleration; $\Delta h$ was the water level drop of adjacent pools; and $V$ was the volume of water in a pool.

According to the research results of Larinier et al., the volumetric energy dissipation rate should not be greater than $150-200 \mathrm{~W} / \mathrm{m}^{3}[12]$. After calculation, the volumetric energy dissipation rate of type I fishway was $26.8 \mathrm{~W} / \mathrm{m}^{3}$, and that of type II fishway was $25.1 \mathrm{~W} / \mathrm{m}^{3}$, both meeting the requirements.

\section{CONCLUSION}

(1) The main flows of Type I and Type II nature-like fishway structures exhibited periodic fluctuations in velocity along the direction of water flow, and both had reached the pseudo-uniform condition of flow.

(2) The maximum flow velocity in the Type I structure was $1.063 \mathrm{~m} / \mathrm{s}$, which was $5.3 \%$ lower than that of the Type II structure $(1.123 \mathrm{~m} / \mathrm{s})$. This was because, in the Type II structure, the obstacles more severely narrowed the water flow channel, leading to a greater sudden proportional decrease in the cross-sectional volume of the water flow. Because the flow rate did not change during these 


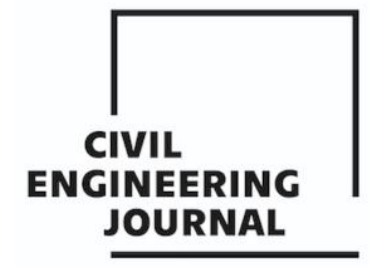

Article no. 63 THE CIVIL ENGINEERING JOURNAL 4-2021

volume fluctuations, the main flow velocity at obstacles in the Type II structure increased more than the main flow velocity at obstacles in the Type I structure.

(3) The average flow velocity in the mainstream of the type I structure increased by $21.1 \%$ compared with that of the Type II structure. The main reason was the local energy loss due to flow expansion downstream of the flow constriction in the central slot in the longer flow path of the type II fishway. The secondary causes included the frictional head losses proportional to the length of the flow path.

(4) In the Type I structure, $9.65 \%$ of the total area had a flow velocity greater than $0.6 \mathrm{~m} / \mathrm{s}$, while $4.05 \%$ of the total area of the Type II structure had a velocity greater than $0.6 \mathrm{~m} / \mathrm{s}$.

(5) The volumetric energy dissipation rate of Type I and Type II nature-like fishway were 26.8 and $25.1 \mathrm{~W} / \mathrm{m}^{3}$ respectively, both meeting the requirements.

\section{ACKNOWLEDGEMENTS}

This work was supported by Sichuan Agricultural University (grant number: 2121997944, 065H0600, 1921993122, 2021993131).

\section{REFERENCES}

[1] Mao X, Li J, An R, Zhao W, Li K., Li R, Deng Y, Liang X., Yang M, Zhang J., Tang K., 2019. Study of key technologies for fishways in the plateaus of western China. Global Ecology and Conservation, vol. 20, e00755.

[2] Mao X., 2018. Review of fishway research in China. Ecological Engineering, vol. 115: 91-95.

[3] Nyqvist D, Elghagen J, Heiss M, Calles O., 2018. An angled rack with a bypass and a nature-like fishway pass Atlantic salmon smolts downstream at a hydropower dam. Marine and Freshwater Research, vol. 69(12): 1894-1894.

[4] Gustafsson S., 2012. Macroinvertebrate colonization of a nature-like fishway : The effects of habitat design. Ecological Engineering, vol. 61(19): 345-353.

[5] Li G, Sun S, Zhang C, Liu H, Zheng T., 2019. Evaluation of flow patterns in vertical slot fishways with different slot positions based on a comparison passage experiment for juvenile grass carp. Ecological Engineering, vol. 133: 148-159.

[6] Tamario C, Degerman E, Donadi S, Spjut D, Sandin L., 2018. Nature- like fishways as compensatory lotic habitats. River Research and Applications, vol. 34(3): 253-261.

[7] Muraoka K, Nakanishi S, Kayaba Y., 2017. Boulder arrangement on a rocky ramp fishway based on the swimming behavior of fish. Limnologica - Ecology and Management of Inland Waters, vol. 62: 188-193.

[8] Li S, Ding X, Liu D., 2014. Review of natural-like fishway. Yangtze River, vol. 96: 70-73. (in Chinese)

[9] State Key Laboratory of Hydraulics and Mountainous River Development and Protection, Sichuan University, 2016. Hydraulics(5th edition)(Volume one) 533 pp. (in Chinese)

[10] Chen K, Tao J, Chang Z, Cao X, Ge H., 2014. Difficulties and prospects of fishways in China: An overview of the construction status and operation practice since 2000. Ecological Engineering, vol. 70: 8291.

[11] Mao X, Zhang J, Tang K, Zhao W., 2019. Designs for T shape fishways. The Civil Engineering Journal 2019, vol. 28 no. 2: 270-280.

[12] Larinier M, Travade F, Porcher J., 2002. Fishways: biological basis, design criteria and monitoring. 